\title{
COMPARISON OF PROPENSITY TO FALLS IN MALE AND FEMALE ELDERLY AND ITS CORRELATION BETWEEN THE BALANCE AND COGNITION LEVEL
}

\author{
Élcio Alves Guimarães ${ }^{1}$, Kennedy Rodrigues Lima², Flávia Fernandes Oliveira', Renato Mota da Silva², \\ Lucas Resende Sousa³ ${ }^{3}$ Kelly Duarte Lima Makhoul', Cristina de Matos Boaventura'
}

\begin{abstract}
Background: Aging is a dynamic, progressive and physiological process, accompanied by morphological and functional changes, as well as biochemical and psychological changes, resulting in a decrease in the functional reserve of organs and system. With aging, functional losses occur, so the elderly have a greater predisposition to falls. Objective: To compare the propensity to falls between elderly men and women correlating with the level of cognition and balance. Methods: The sample consisted of 60 elderly people, of which 30 were male and 30 were female both aged 65 to 80 years. The propensity to falls was assessed using the "Timed Up and Go" and "Functional Reach" tests, and the state of cognition was assessed by the test "Mini-Mental State Examination". Results: The results obtained with Time Up and Go, Functional Reach and the Mini-Mental State Examination, indicated that, as the values of one of the variables increase, the values of the other variable increase too; as the values of one of the variables decrease, the values of the other variable increase too. Conclusions: It can be concluded that there was no increased risk of fall when compared the genders; but the female presented altered cognitive deficit.
\end{abstract}

Key words: Elderly, Cognition, Balance, Falls.

\section{INTRODUCTION}

Aging is a phenomenon that strikes all human beings and is characterized as a dynamic, progressive and irreversible process, closely linked to biological, psychic and social factors ${ }^{(1)}$. In developing countries, such as Brazil, the elderly are those who are over sixty years old ${ }^{(2)}$. The aging of the population is a worldwide phenomenon. The World Health Organization (WHO) predicts that by 2025 there will be 1.2 billion people over the age of 60 , with people with 80 and over being the fastest growing segment of the population. In Brazil, the forecast is that by 2020 there will be 30.8 million elderly people, or $14.2 \%$ of all Brazilians ${ }^{(3)}$. The decline in functions that are manifested in aging over time tend to increase at a rate that varies from one organ to another. These differences are due to the unequal conditions of life and work, which these elderly people have undergone ${ }^{(4)}$. One of the major changes that occurs in the musculoskeletal system, leading to gradual loss of muscle mass, is known as sarcopenia. The direct consequence is the decrease of muscle strength, associated to disorders of balance, reduction of walking speed and functional decline, which predispose to falls $s^{(5)}$. The ability of the subject to remain upright, effectively correcting body movements, and responding to external stimuli, are strategies of postural control essential to activities performed in daily life. After 65 years, up to $30 \%$ of the elderly have altered balance and posture, with progressive worsening over the years. In most cases, the lack of balance can not be attributed to a specific cause but to a compromise of the balance system as a whole (including afferent and efferent neural pathways and the musculoskeletal components effecting the postural response) $)^{(6)}$.

During the natural aging process, occurs a decline in the somatosensory (proprioceptive), visual and vestibular systems that control the balance ${ }^{(7)}$. The balance is the result of the harmonious interaction of various systems of the human body: vestibular, visual, somatosensory and musculoskeletal. Each system has components that, with the aging process, can suffer functional losses that difficult the functioning and execution of the motor response responsible for maintaining the control of posture and body balance, which can generate functional losses for the elderly due to falls and increase levels of morbidity and mortality in this population, as a consequence of a fracture ${ }^{(8)}$. Concerning about the cognition, one of the

Corresponding author: Élcio Alves Guimarães. Address: Av Dos Vinhedos, 900 Bairro Morada da Colina, Uberlândia - MG, Brasil. CEP 38411 -159.

Phone: +55 34 99687-4951. E-mail: elcio@unitri.edu.br

${ }^{1}$ Centro Universitário do Triângulo (UNITRI), Uberlândia - MG, Brasil.

Full list of author information is available at the end of the article.

Financial support: The authors declare that there was no financial support.

Submission date 08 January 2018; Acceptance date 05 March 2018; Publication date 23 May 2018 
expected occurrences with advancing age is its decline. The processes and functions that underlie cognition are affected in different ways during the aging process ${ }^{(9)}$. Memory difficulties are complaints that can often be related to age. Maintaining a good memory is vital for aging, because of its association with autonomy and independence. Memory loss complaints can not be assessed in isolation. Mood disorders, anxiety, social isolation and other factors may be present in the life of the elderly, compromising health and favoring cognitive decline ${ }^{(10)}$.

There are several tests in the literature that evaluate balance, cognition and therefore the risks of falls. The assessment of cognition can be performed through the Mini Mental State Examination (MMSE) validated in $1975^{(11)}$. And some tests are functional mobility test - "Timed Up and Go (TUG)" validated in $1991^{(12)}$ and the Functional Reachtest (FRT) validated in $1990^{(13)}$. This work contributed to the deepening of the physiological changes presented in an elderly person, which leads to frequent falls, thus helping them to minimize and prevent such falls in their daily lives and improve their quality of life. Therefore, the objective of the present study was to compare the propensity for falls among elderly men and women.

\section{METHODS}

The non-probabilistic sample for convenience consisted of 60 elderly people, 30 of whom were male and 30 were female, aged 65 to 80 years, coming from the Physiotherapy Clinic of the Centro Universitário do Triângulo-UNITRI, in Uberlândia/MG. Our inclusion criteria were elderly people aged 65 to 80 years; wandering elderly; without visual deficits; in good health; and who signed the Free and Informed Consent Form. The exclusion criteria was elderly over 80 years and under 65 years; non-wandering elderly; visually impaired (blind); presented signs and symptoms that jeopardized their health during the test; and those that did not sign the informed consent form. Authorization was obtained from the person in charge of the place where the research was carried out. The project was submitted and approved by the Research Ethics Committee of the Centro Universitário do Triângulo, with number 968.266. All the subjects received clarification on the objectives of the study and signed the Free and Informed Consent Form for the accomplishment of the research.

\section{Method}

The data collection was carried out in March and April of 2015 in the Laboratory of Physiotherapy of the Centro Universitário do Triângulo-UNITRI. The tests TUG and FRT were used to evaluate the propensity to falls. TUG is a balance test commonly used to examine functional mobility. The test requires the individual to stand up, walk 3 meters, turn around, walk back and sit. The time taken to complete the test is strongly correlated to the functional capacity level. If the subjects took up to 20 seconds to complete the task, he was considered independent in his basic daily activities, if the task was performed in a time greater than 30 seconds he had an increased risk of falls and functional dependence. For the application of the TUG test were used a chair without armrests, a Vollo digital chronometer and data annotation tokens. Prior to the start of the examination the volunteers received information about the execution of the test and started the test only when they heard the examiner's command voice. At the beginning of the timing the volunteer started from the initial position with his back resting on the back of the chair, upper limbs along the one's body and feet parallel to the floor, raised from the armless chair, walked the distance of 3 meters and returned to the chair in the shortest time possible. Volunteers were allowed to take the test twice, the first being for apprenticeship only (the volunteer was not allowed to receive any help from another person during the test).

The FRT test was used to evaluate the anteroposterior stability, measuring the anterior maximum displacement with the arms outstretched, and in standing position. During this test, the volunteer was asked to stretch as far forward as possible, from a comfortable standing position. The volunteer maintained the upper limbs at the level of a ruler attached to the wall at the same height of his acromion, the examiner was positioned very close to the ruler in order to record the initial and final reach position to then obtain the displacement measured in centimeters. The subject that had a range of less than $15 \mathrm{~cm}$ had the risk of falls, and score of $15 \mathrm{~cm}$ or higher, the volunteer had a reduced risk of falls. This measure tests the volunteer's ability and willingness to move voluntarily to the edges of his or her support base.

For the evaluation of the cognitive profile of the volunteers was used MMSE test that involves two categories of responses, verbal and nonverbal. The verbal sub-tests measure, in particular, space-time orientation, immediate memory, recall and memory of procedure, attention and language. The non-verbal sub-tests measure perceptual-motor coordination and instruction comprehension. The MMSE consists of 30 categorical questions and the score is made as follows: 30 to 26 points: preserved cognitive function; 26 to 24 points: not suggestive alteration of deficit; 23 points or less: suggestive of cognitive deficit; Scores above 26 points are considered optimal and reflect normal cognitive.

\section{RESULTS}

A total of 60 patients participated in this study, 30 (50\%) of the male gender and 30 (50\%) of the female gender. In the TUG test, no volunteer took more than 20 seconds to complete it, and were considered independent in their basic daily activities.

In the TUG test, no volunteer took more than 20 seconds to complete the test and were therefore considered independent in their basic daily activities in the FRT used to evaluate the anteroposterior stability by measuring maximum displacement with the arms outstretched, and standing, most of the 
volunteers obtained a range greater than $15 \mathrm{~cm}$ away, but in females in which they concede at the age of 65 years they obtained a range of less than $13 \mathrm{~cm}$, which is attributed the risk of falls, both male volunteers and female volunteers within the 80 -year age group had excellent scores with scores higher than 26 points, however, volunteers of both sexes in the 65-year age group had scores below the 23 points indicating suggestive of cognitive deficit, as shown in table 1.

Table 2 shows the classifications obtained by the volunteers in the Functional Reach Test, according to the frequencies and corresponding percentages, according to gender and total results, among all male volunteers 30 (100\%) were classified as having decreased risk of falling with a displacement distance above $15 \mathrm{~cm}$ and among female volunteers 01 (3.33\%) was classified as risk of falling with a displacement distance below $15 \mathrm{~cm}$.

Table 3 shows the classifications obtained by the volunteers in the "Mini Mental State Examination", with the corresponding frequencies and percentages, according to gender and total results, being that a large part of the volunteers of both sexes obtained scores between 26 to 30 points were considered with

Table 1 - Age, Timed Up and Go Test, Functional Reach Test and the Mini Mental State Examination, according to the gender of the patients.

\begin{tabular}{ccccc}
\hline & Minimum & Maximum & Mean & $\begin{array}{c}\text { Standard } \\
\text { Deviation }\end{array}$ \\
\hline Male & & & & \\
Age & 65 years & 80 years & 72 y. and 2 m. & 4 y. and $6 \mathrm{~m}$. \\
TUG & $6{ }^{\prime \prime}$ & $13^{\prime \prime}$ & $10^{\prime \prime}$ & $2^{\prime \prime}$ \\
FRT & 17 & 35 & 28.23 & 4.33 \\
MMSE & 20 & 30 & 27.40 & 2.84 \\
Female & & & & \\
Age & 65 years & 79 years & 70 y. and $4 \mathrm{~m}$. & 4 y. and 9 m. \\
TUG & $6{ }^{\prime \prime}$ & $12^{\prime \prime}$ & $9{ }^{\prime \prime}$ & 6.24 \\
FRT & 13 & 44 & 26.77 & 3.29 \\
MMSE & 19 & 29 & 26.00 &
\end{tabular}

Note: TUG = Time-Up and Go test; FRT= Functional Reach Test; MMSE= Mini Mental State Examination; $y=$ years; $m=$ months.

Table 2 - Functional Reach Test with the corresponding percentages, according to gender and total results.

\begin{tabular}{|c|c|c|c|c|c|c|}
\hline \multirow{2}{*}{ Classifications } & Male & Male & Fem & Fem & Total & Total \\
\hline & Frq & $\%$ & Frq & $\%$ & Frq & $\%$ \\
\hline $\begin{array}{l}\text { Under } 15 \mathrm{~cm}-\text { risk } \\
\text { of falls }\end{array}$ & 00 & 0.00 & 01 & 3.33 & 01 & 1.67 \\
\hline $\begin{array}{l}\text { Above } 15 \mathrm{~cm}- \\
\text { reduced risk }\end{array}$ & 30 & 100.00 & 29 & 96.67 & 59 & 98.33 \\
\hline Total & 30 & 100.00 & 30 & 100.00 & 60 & 100.00 \\
\hline
\end{tabular}

Note: $\mathrm{Frq}=$ frequency; $\mathrm{cm}=$ centimeters. their preserved cognitive function, totaling 23 (76.67\%) of the male volunteers and 21 (70.00\%) of the female volunteers.

In order to verify the existence or not of significant differences between the values obtained with the male and female participants, in relation to age and the results obtained in the three tests, was applied to the relevant data the Mann-Whitney $U$ test as used in the study of SIEGEL $(1975)^{(14)}$. The level of significance was set at 0.05 in a bilateral test. The results are shown in table 4.

According to the results shown in table 4, significant differences were found between the results of the MMSE variable, and the highest values were obtained by the male patients. In order to verify the existence or not of significant correlations, between the values obtained with the patients, in the three tests and considering the ages, the Spearman Correlation Coefficient was applied to the data in question as in the study of SIEGEL ${ }^{(15)}$. The level of significance was set at 0.05 in a bilateral test. The results are shown in table 5 .

According to the results shown in table 5 , positive and significant correlations were found between the values of the variables: Age and TUG and between Functional and MMSE. This indicates that, as the values of one of the variables increases, the values of the other variable increase too; As the values of one of the variables decreases, the values of the other variable increase too.

Table 3 - Mini Mental State Examination with the corresponding percentages, according to gender and total results.

\begin{tabular}{|c|c|c|c|c|c|c|}
\hline \multirow{2}{*}{ Classifications } & Male & Male & Fem & Fem & Total & Total \\
\hline & Frq & $\%$ & Frq & $\%$ & Frq & $\%$ \\
\hline $\begin{array}{l}\text { Suggestive } \\
\text { cognitive deficit - } \\
23 \text { pts or less }\end{array}$ & 04 & 13.33 & 07 & 23.33 & 11 & 18.33 \\
\hline $\begin{array}{l}\text { Not suggestive of } \\
\text { deficit - } 24 / 25 \text { pts }\end{array}$ & 03 & 10.00 & 02 & 6.67 & 05 & 8.33 \\
\hline $\begin{array}{l}\text { Preserved cognitive } \\
\text { function - } 26 / 30 \\
\text { points }\end{array}$ & 23 & 76.67 & 21 & 70.00 & 44 & 73.33 \\
\hline Total & 30 & 100.0 & 30 & 100.0 & 60 & 100.0 \\
\hline
\end{tabular}

Note: Frq= frequency; pts= points.

Table 4 - Mann-Whitney test for the values obtained with the male and female volunteers with respect to age and the results obtained in the three tests.

\begin{tabular}{cc}
\hline Analyzed Variables & Probabilities \\
\hline Age & 0.1176 \\
TUG & 0.0916 \\
FRT & 0.2531 \\
MMSE & $0.0377^{*}$ \\
\hline
\end{tabular}

Note: TUG = Timed Up and Go Test, FRT= Functional Reach Test; MMSE= Mini Mental State Examination; $\left({ }^{*}\right) p<0.05$. 
Table 5 - Correlation and associated probabilities, found when applying the Spearman Rank Correlation Coefficient, to the values obtained with the subjects, in the three tests and considering the ages.

\begin{tabular}{ccc}
\hline Analyzed Variables & Correlation & Probabilities \\
\hline Age x TUG & 0.3014 & $0.019^{*}$ \\
Age x FRT & 0.1501 & 0.252 \\
Age x MMSE & -0.0698 & 0.596 \\
TUG x FRT & -0.2126 & 0.103 \\
TUG x MMSE & -0.1107 & 0.400 \\
FRT x MMSE & 0.3876 & $0.002^{*}$ \\
\hline
\end{tabular}

Note: TUG= Timed Up and Go Test, FRT= Functional Reach Test; MMSE= Mini Mental State Examination; Rs= correlation; $\left({ }^{*}\right) p<0.05$

\section{DISCUSSION}

The aging process is characterized by loss of functional capacity that causes greater vulnerability and dependence at this stage of life. The impairment of functional capacity has important implications for the family, the community, the health system and the life of the elderly ${ }^{(16)}$. Independence means that the function is performed without supervision ${ }^{(17)}$. Autonomy can be defined as the freedom to act and make decisions on a daily basis, related to one's life and independence. It can also be understood as the ability to perform activities without the help of another person, with sufficient motor and cognitive conditions to perform these tasks ${ }^{(18)}$. According to a study, independence and autonomy in the activities of daily living ( $A D L^{\prime}$ 's) are related to the integrated functioning of four major functions: cognition, mood, mobility and communication. When these functions are directly or indirectly compromised, in isolation or associated, as a consequence of one or more diseases, impairment can occur in the performance of $A D L s^{(18)}$. In the present study, when evaluating independence through the TUG test in the elderly of both sexes, all were considered independent in their basic ADL's, since no volunteer took more than 20 seconds to complete the test. In a study, when TUG was applied to a population of 60 volunteers of both sexes, with a mean age of 68.57 years, it was found that 37 (61.7\%) of the 60 volunteers scored indexes lower than the normality, presenting functional alteration of balance, thus demonstrating a tendency to have falls in the studied sample ${ }^{(19)}$. Other authors observed when they applied the test in 102 subjects of both sexes, mean age of 78 years, that most of the elderly showed a low risk of falling, suggesting that the volunteers studied had good functional mobility $^{(20)}$. It was demonstrated in the present study that the older the volunteer, the longer it took to perform the task proposed by the test, and when younger, the less time it took to complete the course. So the younger the volunteers were, the more able to carry out their basic ADL's with independence.

The female gender is more vulnerable to problems associated with independence in ADL's, when associated with greater age, depression and progressive loss of memory ${ }^{(21)}$.
In the present study, both sexes presented functional independence, presenting no significant difference when the genders were compared. As one of its consequences, aging brings the gradual decrease of functional capacity, which is progressive and increases with age. Thus, the greatest health adversities associated with aging are the functional disability and the dependence, leading to restriction/loss of skills or difficulty/inability to perform functions and ADL's(19). The level of functional independence and autonomy are currently considered as the real indicators of the health condition of the elderly subject, with or without the presence of injuries. In this context, postural instability, characterized by the perceived difficulty of balance, is of particular importance because it is directly related to the appearance of falls and to the potential of causing dependence, either due to physical sequelae or emotional loss. Fear of falling is a highly limiting factor to the functional independence of the elderly ${ }^{(22)}$.

The fall event can be defined as episodes of imbalance that lead the elderly to the ground. It can be determined by any accidental contact with nearby surfaces ${ }^{(8)}$. Falls represent an important health problem for the elderly population. Approximately one-third of people over 65 years of age will experience one or more episodes of falls in a period of one year $^{(23)}$. According to a study ${ }^{(24)}$, approximately $30 \%$ of subjects over 65 years of age fall at least once a year, of which half are recurring. People of all ages are at risk of falling. However, for the elderly, they have a very relevant meaning, since they can lead to incapacity, injury and death. Analyzing and correlating the functional balance of the elderly with regard to falls events can be considered a difficult task, especially because of the variety of risk factors associated with the senile process that result in functional losses and, consequently, increase the risk of recurring falls ${ }^{(20)}$. It was verified in the present study when using the FRT test, for the evaluation of the balance that both genders did not present risk of falls. In the present study, it was demonstrated that of all the volunteers studied, only one volunteer presented a risk of falls when performed the FRT. When comparing the risk of falls in men and women there was no difference, but a significant difference was observed when the FRT and the MMSE were analyzed, showing that the lower the cognition, the lower the displacement that the subject presented, and the greater the cognition, the greater the displacement that the subject presented. One study, in which the test was applied in a population of 83 elderly women, aged 60 or over, found that the majority of the sample presented a risk of falls ${ }^{(23)}$. According to a study ${ }^{(25)}$, the fall is more frequent in women and its occurrence increases with age, being $32 \%$ of the elderly between 65 and 74 years old, $35 \%$ from 75 to 84 years old and $51 \%$ older than 85 years of age fall yearly. And another study ${ }^{(26)}$, the frequency of falls is greater in women, and is also fourteen times greater in the elderly who need help in the activities of daily life (ADL). Subjects over 80 years of age have a death rate six-times higher than 
people aged between $65-79$, because they fall more often but also because they are more fragile.

Among the factors that affect the occurrence of falls are the gender, with women falling more than $\operatorname{men}^{(27)}$. In the present study, no significant difference was found when comparing the risk of falls among elderly males and females. During the normal aging process, some cognitive functions naturally decrease with age. There is a significant decline in functions, such as attention, memory and executive functions, even in the elderly who are not affected by diseases ${ }^{(28)}$. Cognitive capacity is one of the determinants of quality of life in old ages, since losses in cognitive functions may result in impairment in the physical, social and emotional functioning of the elderly ${ }^{(29)}$. Several changes occur in the central nervous system, such as reduction of brain weight, of the cerebral blood flow and of the number of neurons and slowing of nerve conduction velocity, among others. As a consequence, gradual declines in cognitive functions are seen as common, such as loss of memory and even more pronounced mental deficits. The frontal lobe seems to be the most affected region, mainly in its dorsolateral portion, which is responsible for performing tasks dependent on executive function and working memory. Clinically, it is observed slowing of cognitive processing, reduced attention, difficulty in retrieving learned information, decreased prospective memory and contextual memory ${ }^{(30)}$.

When the cognition in the present study was evaluated through the MMSE test, both genders had cognitive deficits, $13.33 \%$ in males, and $23.33 \%$ in females, demonstrating that gender females had a higher and significant cognitive deficit when compared to males. In this study, during the application of the TUG and FRT tests no difficulty was demonstrated, presenting no intercurrence during its applications. During the application of the MMSE test, many elderly subjects presented difficulties in design drawing and phrases, one reason for this is due to the aging process itself and its physiological alterations. The tests used in the present study were easy to perform and could be applied daily to the physiotherapist in order to assess the risk of falls, thus detecting this risk early in the elderly, and then adopting preventive measures to reduce the incidence of it in this population.

\section{CONCLUSION}

In the present study, it can be concluded that there was no increased risk of fall when compared the genders; but the female presented altered cognitive deficit.

\section{AUTHOR'S CONTRIBUTION}

EAG: study design and guided the entire execution of the study; KDLM: guided the entire execution of the study and critical review; CMB: Data collection and statistical analysis; FFO: Data collection and tabulation of collected data; LRS: statistical analysis; RMS: Data collection, elaboration of the discussion and critical review; KRL: Data collection, statistical analysis, elaboration of the conclusion and review of the article. All authors read and approved the final manuscript.

\section{CONFLICTS OF INTEREST}

The authors declare that there was no conflict of interests.

\section{AUTHOR DETAILS}

${ }^{2}$ Universidade Federal de Uberlândia / Universidade Federal do Triângulo Mineiro (UFU/UFTM), Uberlândia / Uberaba - MG, Brazil. ${ }^{3}$ Universidade Federal de Uberlândia (UFU), Uberlândia - MG, Brasil.

\section{REFERENCES}

1. Fechine BRA, Trompieri N. O processo de envelhecimento: as principais alterações que acontecem com o idoso com o passar dos anos. Revista cientifica internacional. 2012; 1(7): 106-194.

2. Lima DL, Lima MAVD, Ribeiro CG.Envelhecimento e qualidade de vida de idosos Institucionalizados. RBCEH. 2010; 7(3): 346-356.

3. Ferreira DCO, Yoshitome AY. Prevalência e caraterísticas das quedas de idosos institucionalizados. REBEn. 2010; 63(6): 991-7.

4. Ferreira OGL, Maciel SC, Silva AO, Santos WS, Moreira MASP. $O$ envelhecimento ativo sob o olhar de idosos funcionalmente independentes. Rev Esc Enferm USP. 2010; 44(4):1065-9

5. Antero-Jacquemin JS, Santos P, Garcia PA, Dias RC, Dias JMD. Comparação da função muscular isocinética dos membros inferiores entre idosos caidores e não caidores. Fisioter Pesq. 2012;19(1): 39-44.

6. Lima GA, Vilaça KHC, Lima NKC, Moriguti CJ, Ferriolli E. Estudo longitudinal do equilíbrio postural e da capacidade aeróbica de idosos independentes. Rev Bra de Fisiot. 2011; 15(4): 272-277.

7. Hernandez SSS, Coelho FGM, Gobbi S, Stella F. Efeitos de um programa de atividade física nas funções cognitivas, equilíbrio e risco de quedas em idosos com demência de Alzheimer. Rev Bra de Fisiot. 2010; 14(1): 68-74.

8. Almeida ST, Soldera CLC, Carli GA, Gomes I, Resende TL. Análise de fatores extrínsecos e intrínsecos que predispõem a quedas em idosos. Rev Assoc Med Bras. 2012; 58(4): 427-433.

9. Diniz AB, Guerra ARFM, Soares RM, Mariz JVB, Cattuzzo MT. Avaliação da cognição, atividade física e aptidão física de idosos: uma revisão crítica. Estudos de psicologia. 2013; 18(2): 315-324.

10. Valcarenghi RV, Costa Santos SS, Barlem ELD, Pelzer MT, Gomes GC, Lange C. Changes in function/cognition and depression in institutionalized elderly who have suffered falls. Acta Paul Enferm. 2011; 24(6):828-833.

11. Folstein MF, Folstein SE, Mchugh PR. "Mini-mental state". A pratical method for grading the cognitive state of patients of the clinician. J Psychiatr Res. 1975; 12(3):189-198.

12. Podsiadlo D, Richardson S. The timed "Up \& Go": a test of basic functional mobility for frail elderly pearsons. J Am Geriatr Soc. 1991; 39(2):142-148.

13. Ducan PW, Weiner DK, Chandler JM, Studenki SA. Functional reach: a new clinical measure of balance. J Gerontology. 1990; 45(6):192-197.

14. Siegel S, Jr Castellan NJ. O caso de k amostras independentes. In: Siegel S, Jr Castellan NJ. Estatística não-paramétrica, para as ciências do comportamento. São Paulo: McGraw-Hill do Brasil; 1975. p. 250.

15. Siegel S, Jr Castellan NJ. Medidas de associação e seus testes de significância. In: Siegel S, Jr Castellan NJ. Estatística não-paramétrica, para as ciências do comportamento. São Paulo: McGraw-Hill do Brasil; 1975. p. 350 .

16. Mareshiro FL, Lopes MCBT, Okuno, FP, Campanharo, CRV, Batista REA. Capacidade funcional e a gravidade do trauma em idosos. Acta Paul Enferm. 2013; 26(4): 389-94.

17. Lisboa CR, Chianca TCM. Perfil epidemiológico, clínico e de independência funcional de uma população idosa institucionalizada. Rev Bras de Enferm. 2012; 65(4): 482-7.

18. Ferreira OGL, Maciel SC, Costa SMG, Silva AO, Moreira MASP. Envelhecimento ativo e sua relação com a independência funcional. Texto contexto enferm. 2012; 21 (3): 513-8. 
19. Alves LV, Taguchi CK, Oliveira IL, Souza MGC. Avaliação da tendência à quedas em idosos de Sergipe. Rev CEFAC. 2014; 16(5): 1389-1396.

20. Bretan O, Júnior JES, Ribeiro OR, Corrente JE. Risco de queda em idosos da comunidade: avaliação com o teste Timed up and go. Braz J otorhinolaryngol. 2013; 79(1): 18-21.

21. Barbosa CMO, Martin JIG. Ajudas externas à memória na intervenção em pessoas idosas com comprometimento mnésico. Psicologia: Reflexão e Crítica. 2012; 25(2): 320-329.

22. Gai J, Gomes L, Nóbrega OT, Rodrigues MP. Fatores associados a quedas em mulheres idosas residentes na comunidade. Rev Assoc Med Bras. 2010; 56(3): 327-332.

23. Mujdeci B, Aksoy S, Atas A. Avaliação de equilíbrio em idosos que sofrem queda e aqueles que não sofrem quedas. Braz J Otorhinolaryngol. 2012; 78(5): 104-109.

24. Maia BC, Viana OS, Arantes PMM, Alencar MA. Consequências das quedas em idosos vivendo na comunidade. Rev Bras Geriatr Gerontol. 2011; 14(2): 381-393.
25. Ansai JH, Glisoi SFN, Oliveira T, Soares AT, Cabral KN, Sera TN, et al. Revisão de dois instrumentos clínicos de avaliação para predizer risco de quedas em idosos. Rev Bras Geriatr Gerontol. 2014; 17(17): 177-189.

26. Lobo AJS. Relação entre aptidão física, atividade física e estabilidade postural. Rev Enf Ref. 2012; ser III(7): 123-130.

27. Pimentel I, Scheicher ME. Comparação da mobilidade, força muscular e medo de cair em idosas caidoras e não caidoras. Rev. Bras. Geriatr. Gerontol. 2013; 16(2): 251-257.

28. Scoralick-Lempke NN, Barbosa AJ, Mota MMPE. Efeitos de um processo de alfabetização em informática na cognição de idosos. Psicologia: Reflexão e Crítica. 2012; 25(4): 774-782.

29. Beckert M, Irigay TQ, Trentini CM. Qualidade de vida, cognição e desempenho nas funções executivas de idosos. Estud Psicol. 2012; 29(2): 155-162.

30. Petroianu A, Capanema HXM, Silva MMQ, Braga NTP. Atividade física e mental no risco de demência em idosos. J Bras Psiquiatr. 2010; 59(4): 302-307. 